\title{
The Research on Classroom Teaching of Oral Chinese as a Foreign Language*
}

\author{
Lin Zhang \\ College of Foreign Studies \\ Guilin University of Electronic Technology \\ Guilin, China 541004
}

\begin{abstract}
This article mainly analyzes the importance of oral Chinese teaching in teaching Chinese as a foreign language, the practicality of oral classroom teaching, the relationship between the cultivation of undergraduates' qualities in Chinese international education and the training of oral teaching ability, and the research on the oral skills of oral English teaching. The research explores the value of oral teaching in teaching Chinese as a foreign language. And at last, we summarize some theories to enhance the teaching ability of oral Chinese for undergraduates in Chinese international education.
\end{abstract}

Keywords-teaching Chinese as a foreign language; oral Chinese teaching; classroom teaching

\section{INTRODUCTION}

Sociolinguistics believes that people's needs for language change with the needs of communication. With the development of globalization and the improvement of Chinese economy, the demand for Chinese as a second language is increasing. In recent years, with the rise of the global Chinese fever and the promotion of the strategy of "the Belt and Road", training excellent teachers of Chinese as a foreign language has become an urgent matter of professional development. The course of teaching Chinese as a foreign language is a part of teaching practice based on the training of oral classroom teaching abilities. This course can well test and develop the teaching quality of Chinese international education majors. And it can effectively connect with the theoretical knowledge and future overseas teaching internship.

\section{RESEARCH ON THE IMPORTANCE OF ORAL TEACHING}

Lv Bisong (1995) put forward two different concepts of "special skill class" and "special target class" in teaching Chinese as a foreign language. He emphasized on the rules of language learning. And he paid attention to communication. And he advocated making the differentiation between class and "colloquial class" which

*This research was financially supported by the Project of Science and Education combined with Cooperative Education Action Plan of Guilin University of Electronic Technology in 2017, in which the content was Research of on the Role of Oral Chinese Teaching Training in Classroom in Training of Professionals of Teaching Chinese to Speakers of Other Languages ( Grant No. CS16028X ) aims at cultivating communicative competence. At the same time, he made scientific distinction between spoken language and written language. He pointed out that "oral language" and "written language" was communicative concepts. That is "pragmatic concepts". Ruan Lirong (2006) randomly investigated 100 selected international students from Beijing Language and Culture University. And he finds that $70.1 \%$ of Chinese learners think "oral communication is an indispensable part of their work and study. To communicate with each other in Chinese is the first purpose. And oral class is the primary goal of learning to read and write.

On the classroom teaching, Chen Xianchun (1999) once remarked that TCFL teachers must acquire Chinese as a foreign language through acquisition. The reason is that most people learn Chinese as a communicative tool. Therefore, skill-based communicative Chinese knowledge must be obtained through repeated exercises. At the same time, Gao Yande et al. (1993) argue that our oral class fails to effectively meet the learning needs of Chinese learners. It is incompatible with the needs of oral English learning. To some extent, it formed a contrast. To sum up, we can see that scholars all agree on the necessity of oral teaching and the importance of building teachers' spoken English. Oral English, as a direct requirement of Chinese learners, also puts forward all-round and multi-level requirements for teachers.

To sum up, under the communicative demand of Chinese learners, oral English teaching ability is one of the abilities that Chinese teachers of foreigners must master. And their status should not be underestimated in the four lesson types of listening, speaking, reading and writing. In Guilin University of Electronic Technology, Chinese international education undergraduate programs in the future training programs in overseas internship among the teaching objects are mostly Thai primary level students. The ability training of oral English teaching can develop teachers' oral teaching ability and improve the quality of overseas internship teaching. Also, it can effectively solve the teaching problems during the internship process.

\section{ON THE PRACTICALNESS OF CLASSROOM TEACHING}

Elbaz (1983) systematically explores "practical knowledge" in pedagogy. She believes that the teacher's "practical knowledge" is difficult to obtain in the theoretical 
learning process. She has pointed out that teachers' knowledge and ability come from practice, which depends on practice and serves practice.

Zhang Jie (2007) argues that the practice of teaching Chinese as a foreign language is actually a practical process for teachers of Chinese as foreigners to apply their own knowledge and abilities. The students of Chinese international education access to knowledge and ability from the teaching practice. And the ability will eventually be used in teaching practice. The process of teaching practice is characterized by suddenness, randomness and complexity. Many problems of teaching can't be solved by the knowledge or ability that teachers had at that time. These specific problems associated with teaching situations have prompted TCFL teachers to continuously enrich and develop their own knowledge and abilities. At the same time, she pointed out that knowledge, ability, and teaching practice are all mutually reinforcing in the process of teachers 'growth. Especially, they are important in the process of teachers' growth. Before the TCFL students participate in the teaching, they have certain teaching theories and certain background knowledge. However, this teaching knowledge acquired in the books can't be directly converted into teaching ability.

In summary, scholars believe that teaching practice is an indispensable part in the training process. The training of oral Chinese teaching in undergraduate international Chinese majors is based on innovative teaching practice. And innovative teaching practice is based on Microteaching. It is a teacher training method developed by Stanford University in 1963. It aims to rapidly improve the teaching special skills of normal students in the short term, which is recognized as an effective way to train teachers. Especially in the shortterm training, the students have "immersive" experience. And then, it would achieve the full grasp of the actual teaching in the classroom. Microteaching activities for each trainee have a great teaching effect. The teaching method would play video. The students in this part of the link have a perceptual understanding of teaching. In the process of analysis, discussion, exchange and evaluation, they would find their own shortcomings in teaching process and other people's teaching strengths. Therefore, it would be effectively translated into teaching ability in teaching reflections. The research on microteaching shows that many teaching skills are not able to be learned through theoretical knowledge. However, the teaching skills of those who are teaching Chinese as a foreign language can be improved with the help of microteaching. For example, body posture, questions and other concepts will have some improvement. And it would be measured immediately after the end of the session and the end of teaching of 150 days. At the same time, the training of oral classroom teaching is different from that of microteaching. The instructor will give guidance and suggestions to the trainees in the church, pointing out the defects of the trainees in the process of classroom teaching. And then, the trainees would make the reflection on the classroom teaching. And it would be internalized as teaching ability. Under the guidance of the instructor, the training of oral classroom teaching ability can be effectively connected with the theoretical knowledge learned in the past and the overseas teaching practice in the future.

\section{RESEARCH ON THE RELATED QUALITY OF} UNDERGRADUATE MAJORS OF THE CHINESE INTERNATIONAL EDUCATION

In the process of teacher training, to train the basic knowledge and ability of teachers in a short time is a practical problem to be solved by curriculum experts. In order to solve this problem, it is necessary to study the composition of the knowledge and ability of teachers of Chinese as a foreign language. We should discuss where the various knowledge and capabilities come from and discuss ways of cultivating teachers' knowledge and abilities. And we should build a model centered on knowledge and ability development.

Based on the teaching work, scientific research work, and organizational and leadership work of teaching and research undertaken by teachers of Chinese as foreigners, Lv Bisong (1989) proposed the professional qualities teachers should have in various positions. TCFL teachers must have the professional knowledge and cultural knowledge of various disciplines. And they have the complex ability. This includes linguistic knowledge, psychology knowledge, pedagogical knowledge, literary knowledge and other cultures. The ability to have teaching practice shows the language, classroom teaching, and communication and organization capabilities. Liu Xun (1996) paid great attention to the cultivation of practical abilities in education. He believes that different teachers of Chinese as foreigners should have the following abilities. First, they should have the systematic theoretical foundation of Chinese linguistics and standardized Putonghua and writing skills. Second, we should grasp the teaching theory and basic principles of Chinese as a second language. And the teachers should have the ability to apply their proficiency in classroom teaching. They should master teaching objectives and different teaching methods. They should have good teaching design ability. They must arrange teaching steps, have compiling and assessing ability. Also, the teachers should have the ability to analyze, judge, evaluate and explain students' learning effectiveness and Chinese proficiency. Thirdly, the teachers should master certain cultural background; understand Chinese culture and ancient literature knowledge literacy, mainly the background knowledge of Chinese language and culture. Fourth, the teachers should master linguistics knowledge. Especially, they should have sociology, psychology, second foreign language learning theory and related education theory. They must know about second language learning and acquisition. The fifth is to have a certain cross-cultural communication skills and intercultural communication. The sixth is to love Chinese international education. "The International Chinese Teachers' Standard" (2015) requires teachers to have the following oral instruction skills. "The teachers should design different teaching steps and exercises according to their teaching purposes. They could adopt effective teaching methods according to Chinese ability and learning purposes of different nationalities of Chinese learners and different 
teaching environments. The teachers should reasonably arrange the teaching activities and effectively guide students in the classroom. It can effectively promote learners' enthusiasm for learning Chinese. The teachers should grasp and understand the relationship between classroom teaching of TCFL and the skills of second language. The teachers can well grasp the commonness and individuality of the specific historical unity".

To sum up the scholars' opinions, the author believes that undergraduate education of Chinese as a foreign language can't be simply understood as bilingual personnel training of Chinese and English. An excellent teacher of Chinese as a foreign language must possess various abilities. The training process must also go through the process "from class to class", "from theory to practice" and "from stage to platform". Teaching Chinese as a foreign language is determined by the relevant qualities of teachers. At the same time, organizational teaching in the classroom directly reflects the qualities of teachers. The teaching links can well test and develop the teaching quality of teachers. In this paper, the author makes an in-depth study on the relevant qualities required by undergraduate majors in international Chinese education. It establishes the teaching link and explores the significance of its existence.

\section{RESEARCH ON THE SKILLS OF ORAL CLASSROOM TEACHING}

The training of classroom teaching skills is an important part of teaching Chinese as a foreign language. The purpose of teaching and teaching methods can't be separated from the cultivation of teaching skills. A mature foreign language teacher must have good skills in teaching Chinese as a foreign language. And then, we could carry on the classroom teaching with scientific and effective teaching skills. On the teaching skills of spoken Chinese, Cheng Meizhen and Zhao Jinming (1985) pointed out, "The main content of phonetic teaching is the imitation of students' phonetic demonstrations of teachers. The theoretical knowledge of phonetics must be avoided to the greatest extent."

At the same time, they also pointed out that the teaching process should start from the easy to the difficult and from the old to the new. It should highlight the heavy and difficult content. And the teachers should repeat the process. At the same time, the teachers should strengthen the visual teaching and improve teaching efficiency. When we talked about the teaching skills of foreign Chinese vocabulary, Lu Jianming (2005) pointed out that the teachers should explain the meaning and usage of words with different methods according to different degrees and different objects. He introduced several methods such as "Icon law", "literal translation", "and taking new law with old rules ","sememe analysis", "simulation method" and "context teaching method". Cheng Meizhen also summarizes nine kinds of speech teaching techniques such as demonstration method, contrast method, exaggeration method, gesture method, trance method, tonal method, resolution method, fixed method and imitation method to help students consolidate the words learned in the text. It would deepen the understanding on the meaning and usage of words. The article also introduces 15 types of practice types such as filling in blanks, making sentences, collocations of words, semantic selection, deducing semantic meaning and forming words into words.

For the teaching rules and conversational training of second foreign language, Cui Yonghua and Yang Jizhou (1997) summarized some common teaching skills of foreign language. For the teaching of "performing" law, they believe that teaching is a performance for teachers. Common examples include the practice of changing characters, impromptu performances, sub-roles, hosting of programs, etc. The discussion teaching can include discussions on texts, photos, diagrams, maps, comic strips, popular topics. "Q \& A" can include scenario quizzes, card tips, associative quizzes, quizzes, etc. At present, the teaching techniques of Chinese as a foreign language mainly focus on the teaching contents and teaching skills of Chinese for foreigners. For example, on the teaching of language conversational skills, $\mathrm{Xu}$ Ziliang (2002) also summarizes skills. A simple "question and answer" can include "situational method", "card tip", "traffic map inquiry", "photo questioning", "associative answer" and "free Q\&A". "Game" law commonly includes the riddles and the action according to the speech performance. The "performance" includes character replacement, character play, sketch, play host, voice show and so on.

Teaching skills also include the teaching of body language as the representative of behavioral language teaching. That is to say, we could assist foreign language teaching through body language. In the early days of teaching Chinese as a foreign language, students can't master the target language. With the limitation of teaching objects, interlanguage may not be able to achieve the desired teaching purposes. The body language can achieve the teaching objectives under certain circumstances. For example, in a speech class, a teacher may use gestures to translate, raise, draw a curve, and play a gesture to instruct the students to perform pronunciation training. When training students to pronounce, teachers can perform exaggerated oral presentations. It would allow students to imitate pronunciation. Students should not necessarily know the linguistic theory, such as pronouncing methods, mouth cavity structures, and pronunciation. Students may feel boring if they learn too many theories.

\section{CONCLUSION}

In summary, as an important part of teaching Chinese as a foreign language, classroom teaching skills come from a great deal of practical research and theoretical foundation. However, there are not many theories on how to form a systematic teaching method for teaching Chinese as a foreign language. Cui Yonghua and Yang Zhizhou (1997) have also explored the reasons for this. The author believes that the current training of classroom teaching mainly comes from teaching practice and teachers' precepts. 


\section{REFERENCES}

[1] Cheng Meizhen, Zhao Jinming. Some problems in basic Chinese phonetics teaching [A]. Proceedings of the First International Teaching Forum of Chinese, Beijing Language and Culture Institute Press, 1985

[2] Chen Xianchun. We can improve Chinese Teaching — The concept of overall design reform for the teaching of Chinese as a second language [J], Journal of Language and Culture Studies (III), Mandarin Teaching Press, 1999.

[3] Cui Yonghua, Yang Jizhou. Classroom teaching skills of Chinese as a foreign language $[\mathrm{M}]$. Beijing: Beijing Language and Culture University Press, 1997.

[4] Confucius Institute Headquarters, Hanban, eds. International Chinese Teachers' Standard: Chinese-English Comparisons [M]. Beijing: Foreign Language Teaching and Research Press, 2015.

[5] Lu Jianming. Teaching Chinese as a foreign language should focus on vocabulary teaching $[\mathrm{J}]$ Chinese ontology research, Foreign Language Teaching and Research Press, 2005.

[6] Luo Xiaolan. Teacher Psychology — Teacher Psychological Analysis [M]. Beijing: China Social Press, 2008.

[7] Lv Bisong. Introduction to teaching Chinese as a foreign language [M]. World Chinese Language Teaching, 1995.

[8] Lu Bisong. Several issues on the professional qualities of teachers of Chinese as a foreign language [J]. Chinese Teaching In The World, 1989 (1): 1.

[9] Liu Xun. A few questions about the training of Chinese teachers [J]. Chinese Teaching In The World, 1996 (2): $101 \sim 102$.

[10] Xu Ziliang. The role of language practice in colloquial automation [J]. Chinese for Foreigners (Episode 2), Shanghai Foreign Language Education Press, 2002. 24

[11] Ruan Lirong. Advanced oral teaching materials and related issues, [D]. Beijing Language and Culture University, 2006.

[12] Zhang Hesheng. Classroom teaching skills of Chinese as a foreign language [M]. Beijing: Commercial Press, 2006.

[13] Zhang Jie. Knowledge and ability structure of teachers of Chinese as a foreign language [D]. Beijing Language and Culture University, 2007.

[14] Elbaz F.Teacher's thinking: A Study of Practical knowledge [M].. London: Croom Helm. 1983, 216. 